\title{
A REFORMA DA GESTÃO DAS REDES ESTADUAIS DE GOIÁS E DO RIO DE JANEIRO SOB A ÉGIDE DA NOVA GESTÃO PÚBLICA
}

\author{
LA REFORMA DE LA GESTIÓN DE LAS REDES ESTATALES DE GOIÁS \\ Y DE RIO DE JANEIRO BAJO EL AMPARO DE LA NUEVA GESTIÓN PÚBLICA
}

THE MANAGEMENT REFORM ON THE ESTATE NETWORK OF GOIAS AND RIO DE JANEIRO UNDER THE SUPPORT OF THE NEW PUBLIC MANAGEMENT

\author{
Sheila Santos de OLIVEIRA ${ }^{1}$ \\ Miriam Fábia ALVES ${ }^{2}$
}

RESUMO: Este artigo se propõe a refletir sobre duas reformas educacionais que foram realizadas a partir do ano de 2011 nos estados de Goiás e Rio de Janeiro, respectivamente conhecidas como "Pacto Educacional Todos pela Educação: um futuro melhor exige mudanças" e "Gestão Escolar Profissionalizada". O foco da análise foi a gestão gerencial proposta por essas reformas e os seus desdobramentos na organização escolar. A análise foi realizada a partir dos documentos que balizaram as reformas nos dois estados e permitiu concluir que em Goiás e no Rio de Janeiro, os princípios da eficiência e da eficácia, pautadas em resultados mensuráveis, têm influenciado a educação pública estadual, sobretudo pelo controle do trabalho docente por meio da avaliação, do sistema de responsabilização e bonificação. Intensificam-se, a partir da adesão dos governos, os argumentos da Nova Gestão Pública a favor de alterações nas relações Estado/Sociedade e consequentemente, Escola.

PALAVRA CHAVE: Nova Gestão Pública. Pacto Educacional. Gestão Escolar Profissionalizada. Goiás. Rio de Janeiro.

RESUMEN: Este artículo se propone reflexionar sobre dos reformas educativas que se realizaron a partir del año 2011 en los estados de Goiás y Río de Janeiro, respectivamente conocidas como "Pacto Educativo Todos por la Educación: un futuro mejor exige cambios" y "Gestión Escolar Profesional". El enfoque del análisis fue la gestión gerencial propuesta por esas reformas y sus desdoblamientos en la organización escolar. El análisis fue realizado a partir de los documentos que balizaron las reformas en los dos estados y permitió concluir que en Goiás y en Río de Janeiro, los principios de eficiencia y de eficacia, pautados en resultados mensurables, han influido en la educación pública estatal, sobre todo por el control del trabajo docente por medio de la evaluación, del sistema de responsabilidad y bonificación. Se intensifican, a partir de la adhesión de los gobiernos, los argumentos de la Nueva Gestión Pública a favor de alteraciones en las relaciones Estado / Sociedad y consecuentemente, Escuela.

\footnotetext{
${ }^{1}$ Pontifícia Universidade Católica de Goiás (Puc), Goiânia - GO - Brasil. Professora substituta da PUCGoiás.

${ }^{2}$ Universidade Federal de Goiás (Ufg), Goiânia - GO - Brasil. Professora do Programa de Pós-Graduação em Educação da UFG. E-mail: miriamfabia@gmail.com.
} 
PALABRAS CLAVE: Nueva Gestión Pública. Pacto Educativo. Gestión Escolar Profesional. Goiás. Rio de Janeiro.

ABSTRACT: This article intents to reflect on two educational reforms that were carriedout since 2011 in the states of Goias and Rio de Janeiro, respectively known as "Education Pact All for Education: a Better Future Requires Change" and "Professional School Management". The focus of the analysis was the management proposed by these reforms and their development in the school organization. The analysis was based on the documents that established the reforms in the two states. It allowed us to conclude that, in Goias and in Rio de Janeiro, the principles of efficiency and effectiveness, based on measurable results, have influenced the State public education, the teaching work through evaluation, the system of accountability and the bonus. From the adherence of the governments, the arguments of the new public management are intensified in favor of changes in the State-Society relationship and consequently, in the School.

KEYWORDS: New Public Management. Educational Pact. Professional School Management. Goias. Rio de Janeiro.

\section{Introdução}

Vivenciamos, em 2017, no país, um momento de grande complexidade no que diz respeito à condução política e econômica das instituições do Estado. Não sem precedentes, esse momento revela as alterações conjunturais que vinha ganhando forma e conteúdo, sobretudo, a partir da década de 1990. Sob a justificativa de que é necessário resolver a crise fiscal por que passa o país, o governo brasileiro aprovou a Emenda Constituição N. 95/2016 que impõe um congelamento de 20 anos aos gastos primários, dentre os quais educação e saúde. Nesse cenário, se discute uma série de reformas que tem por objetivo privatizar o estado brasileiro: parceria público-privado, organização social na gestão do serviço público, privatização das empresas estatais. Se por um lado, a privatização ganha a cena, por outro, o discurso de depreciação do serviço público legitima reformas no interior do estado e concretiza a lógica reformista que estava em voga nos anos de 1990, que projeta um novo modelo de estado pautado nos princípios da nova gestão pública.

Essa lógica reformista vem acontecendo ao longo da última década na esfera dos governos estaduais e ganhando destaque no projeto de educação que se quer implementar. Este artigo se propõe a refletir sobre duas reformas educacionais que foram realizadas a partir do ano de 2011 em Goiás e no Rio de Janeiro, respectivamente conhecidas como "Pacto Educacional Todos Pela Educação: um futuro melhor exige

RPGE - Revista on line de Política e Gestão Educacional, Araraquara, v. 22, n. esp.1, p. 177-192, mar., 2018. 
mudanças" e "Gestão Escolar Profissionalizada". O foco da análise foi a gestão gerencial proposta por essas reformas e os seus desdobramentos na organização escolar. A análise foi realizada a partir dos documentos de proposição das reformas nos dois estados.

O artigo está organizado em dois blocos: no primeiro a discussão das reformas que implementaram a nova lógica da gestão pública no Brasil e no segundo a análise das reformas em Goiás e no Rio de Janeiro.

\section{Reforma do estado e uma nova lógica de fazer a gestão pública}

Nos anos de 1990 o país, recém saído de um regime ditatorial, impregnado pelos desejos democráticos de justiça social e igualdade, conviveu com um Estado reformista que chegava ao poder assumia os princípios e fundamentos de um modelo de gestão antagônicos àqueles almejados pela população. Foi nesse cenário que inúmeras reformas ganharam visibilidade, especialmente a partir do ano de 1995, no governo Fernando Henrique Cardoso (FHC). As justificativas para a reforma do estado e sua urgência eram atribuídas à crise fiscal e esgotamento do Estado intervencionista, bem como à ineficiência da tradicional burocracia considerada rígida, centralizada e hierárquica, mais focada no controle dos processos da administração pública do que em seus resultados.

Nesse sentido, o movimento "reformista" propunha superar esses limites implantando "um novo modelo de desenvolvimento que possa trazer para o conjunto da sociedade brasileira a perspectiva de um futuro melhor" (BRASIL, 1995, p. 6). Para tal, empreendeu-se significativa alteração do papel do Estado, buscando sua reestruturação, com a finalidade de alavancar a economia e promover o crescimento do país desfazendo-se da sobrecarga de funções destinadas ao Estado que estariam além das suas atribuições, especialmente na área social. Desse modo, propõe-se que o entendimento da reforma deva se associar à redefinição do papel do Estado que, a partir de então, não assumirá diretamente a responsabilidade pelo "desenvolvimento econômico e social pela via da produção de bens e serviços, para fortalecer-se na função de promotor e regulador desse desenvolvimento" (BRASIL, 1995, p. 12).

Nessa direção, alinhado ao movimento de cunho neoliberal que ocorrera em alguns países da Europa e Estados Unidos, desde a década de 1970, o Brasil transitava de uma administração pública burocrática para uma administração pública de base gerencial, que recebeu forte apoio do Banco Interamericano de Desenvolvimento (BID),

RPGE - Revista on line de Política e Gestão Educacional, Araraquara, v. 22, n. esp.1, p. 177-192, mar., 2018. 
tendo como foco a eficiência no controle dos resultados e a eficácia na ação reguladora do Estado.

As reformas de cunho gerencialistas propõem, entre outras questões, a flexibilização da estabilidade funcional, a inculcação de valores meritocráticos e de produtividade no setor público, aliada à descentralização dos processos decisórios e de execução, o que permitiria ao Estado atender com mais eficiência o cidadão, "cliente privilegiado" de seus serviços. A descentralização implica, portanto, o repasse das responsabilidades, que seriam do Estado, para o setor privado ou demandar as atividades que não têm relação direta com a sua função para a execução do chamado setor "público não estatal" ou terceiro setor. Esse processo denominado "publicização", ou seja, a transferência dos serviços não exclusivos do Estado para o público não estatal, em que esses serviços assumirão a forma de “organizações sociais”, incidirá, sobretudo, nos serviços sociais como saúde e educação. As políticas de descentralização, para Cury (2002, p. 196), quando determinadas por um "governo central poderoso, ganham um sentido de centralização de concepção e descentralização da execução nos níveis subnacionais de governo".

Desta forma, o processo de desregulação do mercado, de privatizações, e a crescente necessidade de articulação entre o setor público e o setor privado, sobretudo, quando da transferência para a esfera pública de práticas empresariais de um lado, e por outro, do ponto de vista político, o desenvolvimento democrático das práticas de participação social, de controle social (transparência pública) e inclusão social, trazem à baila a emergência de uma reforma administrativa do Estado, como resposta à ineficiência da burocracia tradicional, que contemple estratégias focadas na produtividade gerencial, no desempenho e na eficiência: uma "Nova Gestão Pública" (REZENDE, 2009).

Ao se aprofundar na questão, Hood (1991) elenca um conjunto de elementos que seriam constitutivos dessa nova gestão. Dessa forma, o autor fornece subsídios para que se compreenda como a reestruturação administrativa vem alterando as relações entre o Estado, suas instituições, o mercado e a sociedade civil. Nesses termos, em sua obra The public management for all seasons?, ele apresenta uma tabela doutrinal que traduz algumas características da Nova Gestão Pública (NGP), que, em linhas gerais, consiste na mensuração de desempenho a partir de normas e medidas explícitas, na ênfase no controle, na maior concorrência no setor público, na apropriação de práticas do setor privado a serem empreendidas no setor público e na maior disciplina e racionamento do uso dos recursos (HOOD, 1991). A NGP ainda significa pensar no controle de 
organização de pessoas, na descentralização, na definição de metas e indicadores de performance profissional, na flexibilidade, na elevação da disciplina, na redução dos custos do Estado com as políticas sociais e na resistência às demandas sindicais. A intenção das reformas gerenciais, como a NGP, é fazer com que o Estado funcione melhor, a um menor custo (REZENDE, 2009).

Desta forma, Mons (2009) esclarece que a nova gestão pública apresenta um conjunto de diretrizes que alteram o funcionamento das instituições pautadas, principalmente, na relação custo-benefício. Dentro dessa lógica, a educação assume um papel importante nos novos arranjos institucionais e, consequentemente, nas formas de responsabilização. A autora apresenta quatro pilares da nova gestão pública que incidem profundamente no campo educacional, a saber: (1) a produção do serviço público é mensurável; (2) eles devem ser mensurados a partir da utilização de ferramentas específicas cuja validade seja garantida cientificamente; (3) os servidores públicos prestarão contas de suas ações aos gestores do sistema (modelo de avaliação gerencialista) e/ou aos cidadãos (modelo de avaliação democrática); (4) a organização pública deve ser regulada pelos resultados (outputs) e não mais orientada por procedimentos de controle de seus recursos (inputs) (MONS, 2009).

O postulado da NGP, estaria inscrito no desejo de transformação da realidade sob o discurso do "novo": novo liberalismo, novo gerenciamento estatal, nova gestão da educação, novo país. As conquistas e os avanços próprios de nosso processo de construção histórica, pelos conflitos, confrontos e conformações inerentes às relações sociais, fariam parte do antigo, que ficou para trás, confirmando a lógica da descontinuidade que tem marcado a trajetória das políticas educacionais no país. (DOURADO, 2007). Assim, os anseios reformistas são reafirmados por reformas do Estado através da democratização, da descentralização e desconcentração e pela mudança na relação com a sociedade,

Ratificando as características de gerenciamento, são potencializadas as práticas de cooperação internacional do uso do financiamento multilateral na implantação de diversas políticas educacionais. O uso de avaliação externa da gestão pública, através de indicadores quantitativos, mostra-se como instrumento para mensurar a utilização adequada de recursos, bem como a qualidade e performance das políticas avaliadas, enfatizando mais os resultados do que o processo. Nesse contexto, observa-se a objetividade dos processos de descentralização e controle. Esses processos convergem 
com as expectativas sociais democráticas de participação efetiva na administração e acompanhamento do gasto público, sob o discurso da transparência.

Mesmo sendo um desafio para a gestão, observa-se a presença, na educação, da formulação de parcerias entre a sociedade civil e o poder público, denominadas pela literatura especializada como Parceria Público-Privada (PPP), que seguem os propósitos descentralizadores de transferência de responsabilidades, poder e controle do Estado para o setor privado ou para o setor público não estatal. De acordo com Robertson e Verger (2012), as parcerias viriam, nesse período, a atender múltiplos interesses e objetivos determinados de ordem ideológica e econômica através de articulações mais amplas entre o Estado e o Mercado, afirmando a lógica das reformas. Os autores destacam ainda que "elas foram um corretivo para a presença demasiada do Estado (keynesianismo), por um lado, e a ausência dele, por outro (privatização)" (p. 1139).

Esse contexto é marcado por medidas pontuais de uma série de políticas focalizadas de atendimento ao ensino fundamental que, segundo Dourado (2007, p. 927), "propiciaram a emergência de programas e ações orientados pelo governo federal aos estados e municípios" cuja concepção estaria centralizada no âmbito federal e sua execução ameaçada pela ausência de regulamentação do regime de colaboração. A descentralização expressa, portanto, apenas o repasse de responsabilidade dos escalões nacionais para os subnacionais. Nesse sentido, Cury (2002, p. 196) sinaliza as dificuldades de municípios e estados cumprirem com tais responsabilidades, ressaltando o risco de haver um deslocamento de atribuições do público para o privado, processo que acarretaria uma maior "competitividade e seletividade, de corte mercadológicas, pouco naturais aos fins da educação".

A história revela, pois, as continuidades e descontinuidades das políticas de governo. As ações descritas até então fazem parte de um complexo mosaico que se constituiu, no caso brasileiro, e buscou se consolidar no período de 1995 até 2002. Embora tenha havido alguns avanços nesse período, como, por exemplo, a razoável recuperação da crise de desvalorização do real e progressos em relação à expansão da oferta de vagas para o ensino fundamental, FHC não logrou o sucesso na execução de toda sua pretensiosa agenda de gestão, autodenominada de "reforma".

A eleição e posse de Luís Inácio Lula da Silva, como presidente do Brasil em 2003, representou a vitória de forças mais democráticas e populares no comando do governo federal, possibilitando canais de participação e interlocução com outras organizações e com a sociedade civil organizada. No entanto, nos dois mandatos o governo Lula seguiu a agenda da gestão gerencialista, o que pode ser constatado ao analisar as proposições do Plano Plurianual (PPA) 2004-2007 que ratificam uma gestão 
baseada nas matrizes da Nova Gestão Pública. O PPA apresenta como forma de equacionar os problemas sociais e alcançar os objetivos de maior equidade, justiça social e inclusão, o fortalecimento institucional e a governança, bem como a gestão de programas, utilizando-se de ferramentas de gestão e conceitos muito conhecidos na administração geral e de empresas. Esses programas são orientados pela lógica da NGP: gestão por resultados, mensuração de impactos na sociedade, otimização dos recursos e dos processos de trabalho por meio de parâmetros de desempenho e regras mais flexíveis, ancorado em formas e estratégias diferenciadas de gestão sob o auxílio fundamental das tecnologias da informação e comunicação e inovações gerenciais.

No PPA educação de qualidade é apresentada como elemento que irá impactar na competitividade econômica e na equidade social, o que reafirma a análise de Afonso (2000) acerca das políticas educacionais, compreendidas como retórica da mudança, da inovação ou da reforma. Para o autor as políticas educacionais "não estão necessariamente orientadas para a resolução de problemas do campo educacional, embora essa possa ser a razão apresentada" (p. 56). As transformações pretendidas no campo educacional estão estreitamente relacionadas com as condições econômicas para o desenvolvimento e a promoção do país no âmbito nacional e extrafronteiras e, ainda, as condições necessárias para afirmação do Estado, ou como afirma o PPA 2008-2011 “A educação de qualidade representa, portanto, um objetivo estratégico sem o qual o projeto de desenvolvimento nacional em curso não se realiza" (BRASIL, 2007, p. 16).

No segundo mandato do Governo Lula (2007-2010) foi lançado o Plano de Desenvolvimento da Educação (PDE) que nas ações propostas, explicitamente, indicam a preocupação do governo com os maiores problemas que afetam diretamente a qualidade da educação, como a repetência, a evasão, o processo ensino-aprendizagem e a valorização do magistério, dentre outros. Para a superação desses entraves, o PDE apresenta como solução o Índice de Desenvolvimento da Educação Básica (IDEB), cujas metas a serem cumpridas pelos entes federados são definidas por indicadores ${ }^{3}$, e pelos testes padronizados. Os instrumentos de avaliação do desempenho escolar são estandardizados cuja função normativa, que lhes é peculiar, opera a partir de dados quantificáveis e mensuráveis, tomando as partes pelo todo. De fato é o modelo ideal para estimular a competitividade, as comparações e acabou justificando a reforma dos

${ }^{3}$ O IDEB é resultado do produto entre o desempenho e o rendimento escolar. Assim, os indicadores combinam as notas dos estudantes obtidas nos testes padronizados (SAEB e Prova Brasil) com as informações sobre aprovação e rendimento escolar.

RPGE - Revista on line de Política e Gestão Educacional, Araraquara, v. 22, n. esp.1, p. 177-192, mar., 2018. 
sistemas estaduais e municipais pautadas em busca de resultados no IDEB. Ser a melhor rede nesse ranking passou a representar qualidade de educação, bem como sinônimo de boa gestão da educação.

Dilma Rousseff, presidenta do Brasil no período de 2011-2014, anuncia no Plano Plurianual (2012-2015), intitulado "Mais Brasil, mais desenvolvimento, mais igualdade, mais participação", que pretendia atuar com políticas inovadoras "que garantam os direitos dos que mais precisam", realçando o papel indutor e promotor de mudanças do Estado. A visão de futuro se expressa pelos valores de "soberania, democracia, justiça social, sustentabilidade, diversidade cultural e identidade nacional, participação social e excelência na gestão" (BRASIL, 2011, p.18). Entretanto, para alcançar o horizonte almejado com base nesses valores, o Estado deveria promover a conjugação de esforços, meios e recursos de governo, setor privado e sociedade. Nesse PPA a educação é considerada,

[...] fundamental e que constitui condição para a convergência de condições econômicas e sociais entre as regiões, acompanhada da tendência à interiorização, é a educação, determinante para a inclusão social, a efetivação de direitos, a inovação, as atividades econômicas intensivas em conhecimento e a formação de mão de obra nos vários níveis. (BRASIL, 2011, p. 61)

Pode-se avaliar que a concepção de educação responde às expectativas mercadológicas ainda mais quando associada a ela encontram-se as expressões "desconcentração de recursos cognitivos" e "estoque de conhecimentos", adequando o vocabulário a um lugar que não é o da formação humana, cidadã e integral. Afirma-se, assim, a contradição com o que se tem realizado, no diálogo do governo com a sociedade, e o produzido em uma perspectiva contrária. Exemplifica-se, essa mesma concepção tratada na CONAE (Conferência Nacional de Educação) de 2010 e de 2014 e nos Planos Nacionais de Educação (PNE).

Além dessa perspectiva, o PPA reitera a importância do processo avaliativo em larga escala como instrumento de controle e medição da qualidade da educação. Esses processos relacionam-se com a eficiência e a eficácia da gestão educacional na oferta do produto e de seus resultados. Dessa forma, ratificando o que vem sendo abordado, Oliveira (2015, p. 627) ressalta que:

RPGE - Revista on line de Política e Gestão Educacional, Araraquara, v. 22, n. esp.1, p. 177-192, mar., 2018. 
A orientação de progresso vinculada à eficácia da gestão escolar resume de certa maneira os principais argumentos que sustentam as políticas de mais amplo alcance do Ministério da Educação (MEC) que são dirigidas a um contexto extremamente desigual e diversificado, do ponto de vista econômico, social e cultural. Apesar de predominantemente, sobretudo a partir da gestão Dilma Rousseff que se iniciou em 2011, essa condução instaurar uma contradição fundamental no setor educacional, já que os movimentos sociais que se constituíram em base política importante dos governos Lula e Dilma apresentam outras racionalidades, concepções e práticas pedagógicas, como pode se observar nos documentos resultantes das duas últimas conferências nacionais de educação. Não obstante a contradição instaurada no governo federal, ela é ainda maior em âmbito nacional, na relação com os estados e municípios, pelo fato de ser o Brasil um país federativo.

Insere-se nessa contradição a concepção do estado do Rio de Janeiro e do estado de Goiás que agrega a ideia de transformação do quadro educacional e melhoria da qualidade à eficácia da gestão. Esses Estados vêm adotando medidas para mensurar o desempenho, introduzindo práticas do setor privado para o setor público com foco em resultados e ênfase no controle. Pode-se observar o uso de avaliações externas e internas, a divulgação de "boas práticas" (práticas a serem padronizadas pelo sucesso no alcance de metas), premiações e bonificações. A utilização dessas estratégias sinaliza alterações na gestão escolar e no cotidiano, especificamente do ponto de vista do gestor, que se modificam com o trabalho prescrito, elaborado, verticalmente, com os tensionamentos entre a elaboração e a execução do trabalho e sua consequente descaracterização.

\section{Na lógica da Nova Gestão Pública: as reformas na gestão escolar do Rio de Janeiro e Goiás}

No ano de 2011, a Secretaria de Estado de Educação do Rio de Janeiro implementou o seu planejamento estratégico cujo foco é a aprendizagem do aluno. Seguindo a estrutura de um plano estratégico nos moldes gerencialistas, definiu-se a missão, a visão e os valores da instituição “educação”. Assim, o estado assumiria como

Missão - ofertar educação pública e gratuita de qualidade, garantindo o acesso e a permanência do aluno na escola; Visão - atingir grau de excelência na oferta de ensino público, estando entre as melhores redes de ensino do Brasil e do mundo. Valores - Meritocracia, gestão, modernização, eficiência, qualidade, transparência. (RIO DE JANEIRO, 2014, p. 1) 
O planejamento estabelece cinco pontos a serem priorizados para alcançar melhoria da qualidade da educação pública estadual: melhorar o rendimento dos alunos e aumento do interesse pela escola; estímulo dos docentes e servidores; gestão escolar padronizada; maior investimento e eficiência do gasto e aumento da responsividade; transparência e melhoria na comunicação. Para cada problema, foram elaboradas ações/soluções que estariam relacionadas com a implementação do que está sendo entendido, pelo governo, como política pública.

O ponto central da reforma, ou seja, o caminho encontrado para equacionar a má qualidade da educação fluminense foi a "Gestão escolar profissionalizada", uma organização gerencial mais ampla na qual estão inseridas as ações e políticas a serem aplicadas à educação. A gestão escolar profissionalizada instituiu a meritocracia na seleção de diretores a partir de processo de seleção interna, o sistema de reconhecimento por resultados com políticas de bonificação, definição de metas no âmbito da Secretaria de Educação, das Regionais e das Escolas e a implantação de metodologia de gestão com a GIDE.

A reforma foi homologada pelo governador Sérgio Cabral por meio do Decreto n. 42.793, de 6 de janeiro de 2011 estabelecia a reforma desejada para a educação estadual através da implementação do sistema de Gestão Integrada da Escola (GIDE), bem como programas para o aprimoramento e valorização dos servidores públicos da Secretaria de Estado da Educação do Rio de Janeiro. Em consonância com os princípios da NGP a reforma institui a meritocracia, resultados, metas, bonificação por desempenho, avaliações internas e externas, novo modelo de gestão - a GIDE -, análise sistêmica da escola em seus aspectos estratégicos, políticos e gerenciais com foco nos resultados (mensuráveis) do processo ensino aprendizagem, impedindo gastos desnecessários e dispersão de recursos financeiros, materiais e humanos.

Em larga medida, os princípios que pautaram a reforma do Rio de Janeiro foram adotados na "reforma" da educação em Goiás, também datada de 2011, quando a Secretaria de Estado da Educação (Seduc-GO) lançou o programa denominado "Pacto Educacional Todos Pela Educação: um futuro melhor exige mudanças". Tomando como base os resultados do Índice de Desenvolvimento da Educação Básica (IDEB), o documento ressalta a queda no desenvolvimento dos alunos nos anos de 2007 e 2009 em comparação com o ano 2005, o que mantém o estado fora dos primeiros lugares no ranking da educação nacional. O alto número de abandono, principalmente no ensino médio, e o baixo percentual de proficiência dos educandos, nesse nível de ensino, nas 
disciplinas de Língua Portuguesa e Matemática são os principais fatores apontados pela secretaria de educação como indicadores da necessidade de mudança.

Partindo desse contexto, a Seduc-GO iniciou a reforma que apresentava como mote "Ser referência nacional em educação" e para alcançar esse objetivo estabelecia cinco pilares estratégicos: (1) valorizar e fortalecer o profissional da educação, (2) adotar práticas de ensino de alto impacto na aprendizagem do aluno, (3) reduzir significativamente a desigualdade educacional, (4) estruturar sistema de reconhecimento e remuneração por mérito e (5) realizar profunda reforma na gestão e na infraestrutura da rede estadual de ensino. Cada um dos cinco pilares apresenta um plano de ação que perfazem o total de 25 iniciativas das quais destacamos a Escola de Formação de Professores, Academia de Lideranças, currículo referencia, novo ensino médio, investimento em tecnologias, redução da evasão e reprovação, índice de desempenho educacional de Goiás, bonificação por resultados, excelência de gestão e otimização dos gastos. (GOIÁS, 2011). A opção por elencar tais iniciativas não é aleatória, elas fazem parte, entre outras, de um grupo de ações que buscam imprimir uma "nova cultura organizacional” no interior da escola convergindo com as orientações da Reforma do Estado, pautadas nos "imperativos da competitividade e nos impertativos financeiros" (CARNOY, 2002).

O Pilar 5 da reforma "Realizar profunda reforma na gestão e na infraestrutura da rede estadual de ensino", além de inicativas para melhorar a infraestrutura, fortelecer ar relação com a comunidade, integração educacional com os municípios, excelência de gestão da Secretaria, otimização dos gastos. No que tange a otimização dos gastos a previsão era gerar uma "economia prevista de cerca de R\$200 milhões anuais a serem capturados através de redução de temporários, reordenamento de rede, redistribuição de funções administrativas e revisão do custeio". No que diz respeito à excelência da gestão estavam previstas iniciativas de "Revisão e simplificação dos principais processos; sistema de monitoramento em tempo real que mostre o desempenho da rede nos seus 3 níveis - secretaria, regionais e escolas; boletins de transparência para todas as esferas da rede" (GOIÁS, 2011).

O quadro I apresenta a comparação das iniciativas implementadas pelos dois estados que se relacionam com algumas áreas específicas.

Quadro 1: comparativo de iniciativas implementas pelos estados

\begin{tabular}{|c|c|c|}
\hline Área & Rio de Janeiro & Goiás \\
\hline Professores/ & Escola SEEDUC & Escola de Formação de Professores \\
Gestores & Programa de Formação de & Academia de Lideranças \\
& Professores & Residência Educacional \\
& Seleção de Talentos & \\
\hline
\end{tabular}

RPGE - Revista on line de Política e Gestão Educacional, Araraquara, v. 22, n. esp.1, p. 177-192, mar., 2018. 


\begin{tabular}{|c|c|c|}
\hline $\begin{array}{c}\text { Alunos/ } \\
\text { Aprendizagem }\end{array}$ & $\begin{array}{c}\text { SAERJ } \\
\text { Ensino Médio Inovador } \\
\text { Currículo }\end{array}$ & $\begin{array}{c}\text { SAEGO } \\
\text { Novo Ensino Médio } \\
\text { Currículo de Referência }\end{array}$ \\
\hline $\begin{array}{c}\text { Gestão } \\
\text { Educacional }\end{array}$ & $\begin{array}{c}\text { GIDE } \\
\text { Otimização dos gastos } \\
\text { Bonificação }\end{array}$ & $\begin{array}{c}\text { Gestão para resultados } \\
\text { Otimização dos gastos } \\
\text { Bonificação }\end{array}$ \\
\hline $\begin{array}{c}\text { Desigualdade } \\
\text { Educacional }\end{array}$ & $\begin{array}{c}\text { Redução da evasão e repetência } \\
\text { Distorção idade série }\end{array}$ & $\begin{array}{c}\text { Redução da evasão e repetência } \\
\text { Distorção idade série } \\
\end{array}$ \\
& & $\begin{array}{c}\text { Suporte às escolas vulneráveis } \\
\text { Apoio às diversidades }\end{array}$ \\
\hline
\end{tabular}

Fonte: Elaborado pelas autoras

Observa-se que a mudança das palavras não altera o sentido e o objetivo da ação. O quadro revela que, a despeito de diferenças nas nomenclaturas, as iniciativas apresentam intencionalidade e conteúdo similares. Estamos diante de um modelo gerencial, cuja adesão se alastra pelos estados do país, ancorado nos princípios de produtividade e de reprodução e assimilação da realidade. Para Verger e Noramand (2015, p. 599) "nos últimos anos a NGP tem penetrado com força na agenda educativa global". Muitos governos de diferentes países, têm adotado no âmbito educacional reformas guiadas pelos princípios da NGP o que tem alterado, segundo os autores, "de maneira drástica a forma como se concebe a governança das instituições educativas" (VERGER; NORMAND, 2015, p. 600).

Nessa perspectiva pode-se entender o caráter funcionalista da educação e o interesse dos reformistas pela educação. Os governos dos estados em análise, pelas suas respectivas secretarias de educação, instauram no cotidiano escolar novos valores, conceitos e práticas de gestão alicerçada em princípios que alteram, sobremaneira, a relação professor gestor e a ação pedagógica inerente as duas funções; o processo ensino aprendizagem e a natureza e objetivos da educação; a forma de coordenar o trabalho coletivo no cotidiano escolar e, por fim, o que se pretende reduzir, ou seja, as desigualdades educacionais, é reforçado por processos competitivos de mensuração e ranqueamento.

O quadro II, elucida a convergência que se pauta nos princípios explicitados por Hood (1991) com as estratégias dos estados e suas implicações no contexto escolar.

implicações

Quadro 2: de estratégias dos estados de acordo com a NGP e suas

\begin{tabular}{|c|c|c|c|}
\hline $\begin{array}{c}\text { PRINCÍPIOS } \\
\text { NGP }\end{array}$ & $\begin{array}{c}\text { ESTRATÉGIAS - RIO } \\
\text { DE JANEIRO }\end{array}$ & $\begin{array}{c}\text { ESTRATÉGIAS - } \\
\text { GOIÁS }\end{array}$ & IMPLICAÇÕES \\
\hline Estabelecer normas & Plano de metas para a & Plano de metas e & Alteração no cotidiano \\
\hline
\end{tabular}

RPGE - Revista on line de Política e Gestão Educacional, Araraquara, v. 22, n. esp.1, p. 177-192, mar., 2018. 


\begin{tabular}{|c|c|c|c|}
\hline $\begin{array}{l}\text { e medidas } \\
\text { explícitas para } \\
\text { mensurar o } \\
\text { desempenho }\end{array}$ & $\begin{array}{l}\text { Rede } \\
\text { Regionais e escolas } \\
\text { Indicadores de } \\
\text { desenvolvimento da } \\
\text { aprendizagem e do } \\
\text { trabalho escolar } \\
\text { SAERJ }\end{array}$ & $\begin{array}{l}\text { estratégias } \\
\text { Gestão para } \\
\text { resultados } \\
\text { SAEGO }\end{array}$ & $\begin{array}{l}\text { escolar a partir de } \\
\text { prescrições elaboradas } \\
\text { verticalmente } \\
\text { Avaliações estaduais } \\
\text { estandardizadas }\end{array}$ \\
\hline $\begin{array}{l}\text { Manter ênfase no } \\
\text { controle }\end{array}$ & $\begin{array}{l}\text { Controle dos resultados } \\
\text { Currículo Mínimo } \\
\text { Seleção interna para } \\
\text { diretores }\end{array}$ & $\begin{array}{l}\text { Currículo } \\
\text { Referência } \\
\text { Gestão de } \\
\text { Excelência }\end{array}$ & $\begin{array}{l}\text { Legitimação do cargo de } \\
\text { gestor (como administrador } \\
\text { não docente) } \\
\text { Controle sob o } \\
\text { conhecimento legítimo; } \\
\text { Uniformização do currículo } \\
\text { escolar }\end{array}$ \\
\hline $\begin{array}{l}\text { Ampliar a } \\
\text { concorrência no } \\
\text { setor público }\end{array}$ & $\begin{array}{l}\text { Avaliações internas e } \\
\text { externas } \\
\text { Padronização de boas } \\
\text { práticas } \\
\text { Bonificações } \\
\text { Meritocracia }\end{array}$ & $\begin{array}{l}\text { Avaliações internas } \\
\text { e externas } \\
\text { Bonificações } \\
\text { Meritocracia }\end{array}$ & $\begin{array}{l}\text { Uniformização da } \\
\text { aprendizagem } \\
\text { Perda de autonomia do } \\
\text { docente } \\
\text { Responsabilização } \\
\text { Mudança curricular } \\
\text { objetivando o sucesso nas } \\
\text { avaliações } \\
\text { Divulgação dos rankings } \\
\text { Culpabilização do gestor, } \\
\text { professores e alunos }\end{array}$ \\
\hline $\begin{array}{l}\text { Introduzir práticas } \\
\text { do setor privado no } \\
\text { público }\end{array}$ & $\begin{array}{l}\text { Análise com foco em } \\
\text { resultados } \\
\text { Gestão Integrada da } \\
\text { Escola } \\
\text { Método PDCA } \\
\text { Otimização dos gastos }\end{array}$ & $\begin{array}{l}\text { Gestão por } \\
\text { resultados } \\
\text { Academia de } \\
\text { Lideranças } \\
\text { Otimização dos } \\
\text { gastos }\end{array}$ & $\begin{array}{l}\text { Treinamento do docente } \\
\text { para as avaliações } \\
\text { Premiações } \\
\text { Meritocracia } \\
\text { Tensionamentos entre a } \\
\text { elaboração e a execução do } \\
\text { trabalho } \\
\text { Descaracterização do } \\
\text { trabalho docente e do gestor }\end{array}$ \\
\hline
\end{tabular}

Fonte: Elaborado pelas autoras

Portanto, o quadro II evidencia os desdobramentos dessas reformas na organização escolar dos estados em questão que incidem diretamente sobre a autonomia da escola, do trabalho docente e da natureza pública nas redes estaduais. As reformas quebram a autonomia da escola, assegurada na Lei de Diretrizes e Bases da Educação (Lei n. 9.394/1996), uma vez que unificam o currículo a ser executado e estabelecem a avaliação externa como parâmetro de julgamento do trabalho executado bem como ranqueia as instituições escolares a partir dessa avaliação e alteram o cotidiano escolar a partir das prescrições definidas pelo "corpo técnico" que gerencia a reforma. Nesse cenário pouco resta da autonomia da escola para elaborar e executar sua proposta pedagógica, bem como da liberdade de ensinar do professor, que se vê refém do cumprimento das metas.

As reformas produzem uma fissura perigosa na natureza pública nas redes estaduais, pois implementam uma gestão gerencialista, pautada nos princípios da NGP, 
que deve ser aplicada às escolas como se elas fossem uma empresa qualquer. Desconsidera-se nessa lógica a educação como direito de todos e nessa perspectiva um bem público. O diretor, nessa nova lógica, transforma-se em gerente que cumpre as metas externas e controla o trabalho docente. A meritocracia e os prêmios impõem uma lógica de competitividade e rivalidade que quebra a solidariedade necessária para o trabalho coletivo, fundamental para a educação.

\section{Considerações finais}

O presente artigo buscou evidenciar o contexto das reformas educacionais que tomaram cursos a partir da década de 1990 sob a égide de um modelo gerencialista que apresenta como principal postulado a transferência de práticas especificas do campo empresarial para as instituições educativas, enfatizando a melhoria desse setor pela eficácia, eficiência e performance.

Buscando contribuir com o debate, apresentamos os princípios da NGP e sua implementação nos estados de Goiás e do Rio de Janeiro. Considerando as singularidades de cada Rede Pública Estadual de Ensino, compreendemos que estamos diante de um processo que se desenvolveu de forma combinada em um mesmo momento histórico e político indutor das reformas. Os princípios da Nova Gestão Pública, que tem impactado a gestão federal no Brasil, também têm ganhado lastro nas gestões estaduais. Sob o manto de eficiência, eficácia e gestão por resultados, o governo dos estados tem implementado uma série de medidas privatizantes que atingem de forma mais efetiva a saúde e a educação.

O estado de Goiás assim como o do Rio de Janeiro reestrutura seus sistemas educacionais, visando a melhoria da educação, com base no estabelecimento de metas e estratégias que lhes garantissem melhor índice no ranking das avaliações externas, portanto, uma reforma pautada na obtenção de resultados mensuráveis.

O fetiche da quantificação desencadeia a adoção de sistemas metas e avaliação interna nos moldes das avaliações em larga escala que são aplicadas nas escolas no âmbito nacional. Nesse sentido, o processo ensino aprendizagem limita-se a um currículo mínimo ou um currículo referência que, no caso dos dois estados, objetivam atender as demandas de ranqueamento dos testes padronizados internos, externos e a nível internacional. O debate sobre a educação como direito é esvaziado em nome dos bons resultados nas provas, limitado às disciplinas de Língua Portuguesa e Matemática,

RPGE - Revista on line de Política e Gestão Educacional, Araraquara, v. 22, n. esp.1, p. 177-192, mar., 2018. 
o que empobrece ainda mais a formação ofertada. A implementação dos sistemas de avaliações estaduais, em sobreposição ao sistema nacional, reflete a importância que a avaliação em larga escala e a divulgação desses resultados conseguiu alcançar nos últimos anos.

Como vem ocorrendo em vários estados brasileiros, os princípios da eficiência e da eficácia, pautados em resultados mensuráveis, têm redimensionado as ações da administração pública e suas instituições. Essa perspectiva tem influenciado a educação, sobretudo pelos caminhos do controle do trabalho pela avaliação e pelo sistema de responsabilização, como podemos observar no caso dos estados de Goiás e do Rio de Janeiro.

O cenário fica ainda mais complexo quando percebemos que as lutas travadas para democratização da escola e dos sistemas também vão sendo ressignificadas e a consolidação da gestão democrática vai sendo esvaziada de sentido uma vez que a gestão escolar adere completamente à lógica gerencialista e o gestor torna-se liderança, parceiro, gerente, que deve cumprir rigorosamente as metas e obter, a qualquer custo, os resultados previstos.

Por fim, as reformas em curso intensificam, a partir da adesão dos governos, os argumentos da NGP a favor de alterações nas relações entre o estado e a sociedade e consequentemente, a escola. Essas alterações têm causado profundo impacto sobre o fazer da escola pública e na organização do trabalho docente que devem ser entendidos como sinais de alerta sobre os riscos que a educação brasileira tem para os próximos anos, sob pena de um retrocesso irremediável nas frágeis conquistas que obtivemos ao longo de nossa história.

\section{REFERÊNCIAS}

AFONSO, A. J. Avaliação educacional: regulação e emancipação: para uma sociologia das práticas avaliativas contemporâneas. São Paulo: Cortez, 2000.

BRASIL. Plano de Gestão do PPA 2012-2015, Brasília: 2011.

BRASIL. Plano de Gestão do PPA 2008-2011, Brasilia: 2007.

BRASIL. Plano de Gestão do PPA 2004-2007, Brasilia: 2004.

BRASIL. Plano Diretor Plano Diretor da Reforma da Reforma do Aparelho do Estado. Brasília, 1995.

RPGE - Revista on line de Política e Gestão Educacional, Araraquara, v. 22, n. esp.1, p. 177-192, mar., 2018. 
ARNOY, M. Mundialização e reforma da educação: o que os planejadores devem saber. Brasília: UNESCO, 2002.

CURY, R. J. C. A educação básica no Brasil. Educ. Soc., Campinas, v. 23, n. 80, setembro, 2002

DOURADO, L. F. Políticas e gestão da educação básica no Brasil: limites e perspectivas. Educ. Soc., Campinas, vol. 28, n. 100 - Especial, p. 921-946, out. 2007.

GOIÁS, Estado de. Secretaria Estadual de Educação. Pacto pela educação: um futuro melhor exige mudanças. Disponível em:

<http://www.seduc.go.gov.br/especiais/pactopelaeducacao/default.asp>. Acesso: 13 out. 2017.

HOOD, C. A public management for all seasons? Public Adinistration, v. 69, Spring, 1991, p. 3-19. Disponível em: <http://pt.scribd.com/doc/47906982/A-Public-

Management-for-All-Seasons>. Acesso em: 25 maio 2017.

MONS, N. Effets théoriques etréels des politiques d'évaluation standardisée. Revue française de pédagogie, 169 octobre-décembre, 2009.

OLIVEIRA, D. A. Nova gestão pública e governos democrático-populares: contradições entre a busca da eficiência e a ampliação do direito à educação. Educ. Soc., Campinas, v. 36, nº. 132, p. 743-758, jul./set., 2015.

REZENDE, F. C. Desafios gerenciais para a reconfiguração da administração burocrática brasileira. Sociologias, Porto Alegre, ano 11, nº 21, jan./jun., 2009, p. 344365.

RIO DE JANEIRO, Relatório de Gestão e Políticas Públicas, 2014.

ROBERTSON, S.; VERGER, A. A Origem das Parcerias Público Privada na Governança Global da Educação. Educ. Soc., Campinas, v. 33, n. 121, p. 1133-1156, out./dez., 2012.

VERGER, A; NORMAND, D. Nueva gestión pública y educación: elementos teóricos y conceptuales para el estudio de un modelo de Reforma Educativa Global. Educ. Soc., Campinas, v. 36, nº. 132, p. 743-758, jul./set., 2015.

\section{Como referenciar este artigo}

OLIVEIRA, Sheila Santos de; ALVES, Miriam Fábia. A reforma da gestão das redes estaduais de Goiás e do Rio de Janeiro sob a égide da Nova Gestão Pública. Revista on line de Política e Gestão Educacional, Araraquara, v. 22, n. esp.1, p. 177-192, mar., 2018. E-ISSN:1519-9029. 